\title{
Processes governing phytoplankton blooms in estuaries. II: The role of horizontal transport
}

\author{
Lisa V. Lucas ${ }^{1, *}$, Jeffrey R. Koseff ${ }^{2}$, Stephen G. Monismith ${ }^{2}$, James E. Cloern ${ }^{1}$, \\ Janet K. Thompson ${ }^{1,2}$ \\ ${ }^{1}$ United States Geological Survey, 345 Middlefield Road, MS \#496, Menlo Park, California 94025, USA \\ ${ }^{2}$ Environmental Fluid Mechanics Laboratory, Dept. of Civil and Environmental Engineering, Stanford University, Stanford, \\ California 94305-4020, USA
}

\begin{abstract}
The development and distribution of phytoplankton blooms in estuaries are functions of both local conditions (i.e. the production-loss balance for a water column at a particular spatial location) and large-scale horizontal transport. In this study, the second of a 2-paper series, we use a depthaveraged hydrodynamic-biological model to identify transport-related mechanisms impacting phytoplankton biomass accumulation and distribution on a system level. We chose South San Francisco Bay as a model domain, since its combination of a deep channel surrounded by broad shoals is typical of drowned-river estuaries. Five general mechanisms involving interaction of horizontal transport with variability in local conditions are discussed. Residual (on the order of days to weeks) transport mechanisms affecting bloom development and location include residence time/export, import, and the role of deep channel regions as conduits for mass transport. Interactions occurning on tidal time scales, i.e. on the order of hours) include the phasing of lateral oscillatory tidal flow relative to temporal changes in local net phytoplankton growth rates, as well as lateral slashing of shoal-derived biomass into deep channel regions during ebb and back into shallow regions during flood tide. Based on these results, we conclude that: (1) while local conditions control whether a bloom is possible, the combination of transport and spatial-temporal variability in local conditions determines if and where a bloom will actually occur; (2) tidal-time-scale physical-biological interactions provide important mechanisms for bloom development and evolution. As a result of both subtidal and tidal-time-scale transport processes, peak biomass may not be observed where local conditions are most favorable to phytoplankton production, and inherently unproductive areas may be regions of high biomass accumulation.
\end{abstract}

KEY WORDS: Phytoplankton - Estuaries · Model - Transport - Bathymetry · Benthic grazing · Light

\section{INTRODUCTION}

Phytoplankton blooms are important in modifying the elemental composition of surface waters, providing a food source for upper trophic levels, and potentially affecting the aesthetic and health aspects of water for the human population. In the companion to this paper (Lucas et al. 1999, in this issue), we described 2 general factors controlling the 'patchiness' of phytoplankton biomass in natural systems: (1) spatial variability in population dynamics (i.e. the local balance between

•E-mail: llucas@usgs.gov phyytoplankton production and loss), and (2) spatially and temporally variable transports of water and plankton. Local phytoplankton population growth rates may vary significantly in the horizontal due to variations in water column height, as well as differences in turbidity, nutrient concentrations, grazing pressure, and time scales for vertical transport through the water column. Local phytoplankton biomass, on the other hand, depends on transport (i.e. processes which provide communication between subenvironments) as well as on spatially and temporally variable local growth conditions. Thus, the accumulation of phytoplankton biomass (i.e. the occurrence of a 'bloom') and the location of such accumulation depend on (1) whether a sub- 
environment exists within the system where net phytoplankton growth is positive, and (2) what mechanisms transport the phytoplankton population while/after it grows

The companion paper (Lucas et al. 1999) focused on horizontal variability of the local production-loss balance in a vertically well-mixed estuary. The quantity used to represent local growth conditions is $\mu_{\mathrm{eff}}$, the effective rate of depth-averaged phytoplankton population growth at a particular spatial location. This quantity incorporates the effects of depth-variable light availability and photosynthesis, respiration, benthic and pelagic grazing, and a simple representation of nutrient limitation. We explored spatial variations of $\mu_{\text {eff }}$ primarily as a function of bathymetry. In addition, we described the response of $\mu_{\text {eff }}$ to tidal variations in water column height. In this paper, we consider the role of transport in the context of spatially and temporally varying local conditions. Specifically, we explore how interaction of both low-frequency (time scales of days to weeks) and high-frequency (time scales of hours) tidally driven transport with spatial-temporal variations in $\mu_{\text {eff }}$ can determine if and where a bloom occurs. As we will show, the addition of transport greatly changes biomass distributions relative to what we might expect based solely upon $\mu_{\text {eff }}$ distributions.

As in Lucas et al. (1999), we use South San Francisco Bay (SSFB) as a representative case for illustrating tidally driven transport processes and bathymetric variations (i.e. a deep channel flanked by broad shoals) typical of shallow estuaries. (See Fig. 1, and Lucas et al. 1999 for a more detailed description.) In this paper, we use the results of TRIM-BIO, a hydrodynamicbiological model with SSFB as the model domain, as a tool to identify general mechanisms which can control bloom development and location. While the companion paper described the biological aspects of the model, this paper includes a description of the hydrodynamic modeling approach. This work is motivated by observations of complex, temporally varying spatial distributions of phytoplankton biomass (see, for example Huzzey et al. 1990, Lucas et al. 1999, Fig. 1) and the search for the processes causing those kinds of distributions. We emphasize, though, that the purpose of this study is to explore the sensitivity of bloom formation and patchiness to various processes using a numerical model-- not to faithfully reproduce in detail an observed bloom event. Therefore, although we use SSFB as a natural laboratory, implementing geometry, hydrodynamics, and biological parameter ranges characteristic of this estuary, our goal is to gain insight into physical-biological mechanisms potentially important to a broad class of estuaries.

In this paper we address the following questions: (1) How do tidally driven low-frequency (residual) trans- port processes interact with spatial-temporal variability of local conditions to control phytoplankton bloom development and location in an estuary? (2) How do tidally driven high-frequency (tidal-time-scale) transport processes interact with spatial-temporal variability of local conditions to control phytoplankton bloom development and location? (3) Should we expect that regions with local conditions favorable to bloom development (i.e. with large $\mu_{\mathrm{eft}}$ ) will also have high phytoplankton biomass? Will regions with local conditions unfavorable to bloom development (i.e. with small or negative $\mu_{e f i}$ ) necessarily have very low biomass?

Below we demonstrate 5 transport-related mechanisms which arise from the interaction of estuarine tidal flow with local phytoplankton dynamics, and which can potentially control system-level bloom

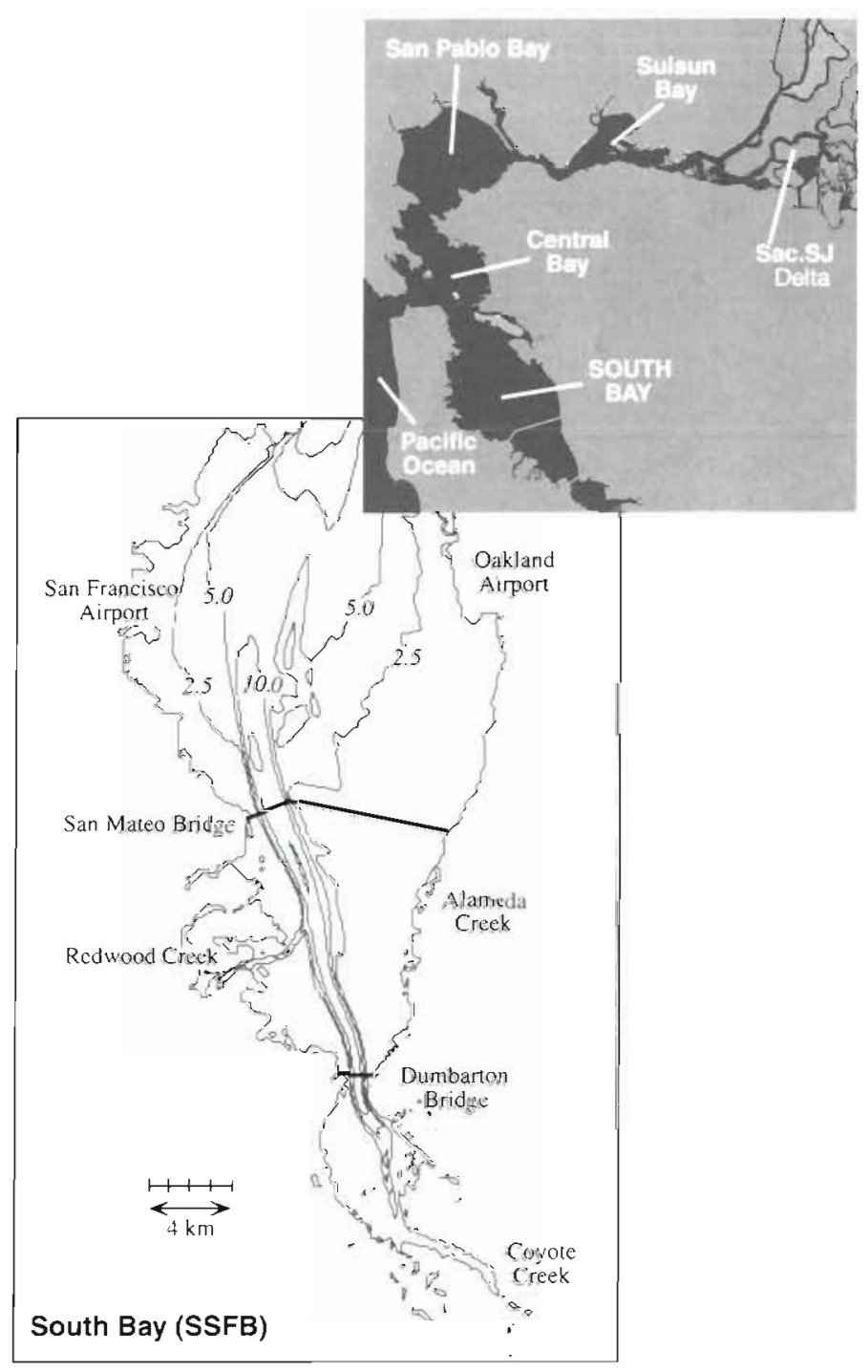

Fig. 1. South San Francisco Bay, with depth contours (mean tide level) shown in meters. Inset shows proximity to northern San Francisco Bay and Sacramento-San Joaquin River Delta 
development and distribution. As we identify these mechanisms, answers to the above questions will become apparent.

\section{MODELING APPROACH}

In Lucas et al. (1999), we described our approach for calculating effective phytoplankton growth rates within TRIM-BIO, a modified form of the hydrodynamic model TRIM2D. Here, we focus on transport-related mechanisms and so below describe the hydrodynamic modeling approach of Casulli (1990a,b), as implemented in TRIM2D, and our adaptation and use of that model.

\section{The TRIM2D hydrodynamic model}

The hydrodynamic model which we adapted for this investigation of horizontally variable phytoplankton dynamics is TRIM2D (Tidal, Residual, Intertidal Mudflat, Casulli 1990a,b, Cheng et al. 1993). This hydrodynamic code is based on the finite-difference approach of Casulli $(1990 \mathrm{a}, \mathrm{b})$ for solving free-surface shallow water flows. The version of TRIM2D used in this study includes modifications by Burau et al. (1993), Gross (1997), and Gross et al. (1999), and was calibrated (using measured tidal currents and surface elevation) and validated (with measured salinity distributions) for SSFB by Gross (1997).

The 2-dimensional, vertically averaged equation set solved by TRIM2D is derived by integrating the 3-dimensional Reynolds-averaged Navier-Stokes equations (with hydrostatic and Boussinesq approximations) over the water column height, $H(x, y, t)$, where $x$ and $y$ are along-estuary and cross-estuary distances, respectively. Horizontal velocities, horizontal diffusivities, and scalar quantities are assumed to be uniform with depth. The resulting 2 -dimensional equation set includes $x$ - and $y$-momentum equations, a depth-averaged continuity equation (accounting for time-variable water column height), and the conservative form of the depth-averaged scalar transport equation:

$$
\begin{aligned}
& \frac{\partial(H C)}{\partial t}+\frac{\partial}{\partial x}(U C H)+\frac{\partial}{\partial y}(V C H) \\
& =\frac{\partial}{\partial x}\left(K_{\mathrm{h}} \frac{\partial(H C)}{\partial x}\right)+\frac{\partial}{\partial y}\left(K_{\mathrm{h}} \frac{\partial(H C)}{\partial y}\right)
\end{aligned}
$$

where $C(x, y, t)$ is the depth-averaged scalar concentration; $U(x, y, t)$ and $V(x, y, t)$ are the depth-averaged horizontal velocities in the $x$ and $y$ directions, respectively; and $K_{\mathrm{h}}$ is the horizontal scalar diffusivity.

Casulli's (1990b) approach is semi-implicit, treating implicitly those terms whose effect on the stability of the solution most restricts the time step, but treating all other terms explicitly for maximum computational efficiency. A linear 5-diagonal system of equations for the free-surface elevation is solved using a preconditioned conjugate gradient method. Advection of momentum is accomplished by the Eulerian-Lagrangian Method, and scalar advection terms may be solved conservatively with any one of several explicit advection schemes (Burau et al. 1993, Gross et al. 1999). The discretized vertically averaged equations are solved on a uniformly spaced grid, with grid spacing $\Delta x=\Delta y=200 \mathrm{~m}$; a typical time step is $0.05 \mathrm{~h}$.

\section{Model adaptation and use}

Incorporation of phytoplankton dynamics into the TRIM2D hydrodynamic model (to produce TRIM-BIO) involved, at the simplest level, addition of a growth term to the scalar advection equation (Eq. 1) for the case of phytoplankton. Thus, for the case where $C=B$ (i.e. where phytoplankton biomass $B\left[\mathrm{mg}\right.$ chl a $\left.\mathrm{m}^{-3}\right]$ is the depth-averaged scalar concentration of interest), Equation 1 becomes the following:

$$
\begin{aligned}
& \frac{\partial(H B)}{\partial t}+\frac{\partial}{\partial x}(U B H)+\frac{\partial}{\partial y}(V B H) \\
& =\frac{\partial}{\partial x}\left(K_{h} \frac{\partial(H B)}{\partial x}\right)+\frac{\partial}{\partial y}\left(K_{\mathrm{h}} \frac{\partial(H B)}{\partial y}\right)+\mu_{\text {eff }} B H
\end{aligned}
$$

$\mu_{\text {eff }}(x, y, t)$ is the effective growth rate of the depthaveraged phytoplankton population (see Lucas et al. (1999) for a description of this quantity). $\mu_{\text {eff }}$ is updated at every grid cell during every timestep and is a function of local turbidity, benthic grazing rate, water column height, and various physiological and environmental parameters. The growth term in Eq. (2) is treated implicitly to ensure scalar positivity and mass conservation. Typical parameter values used in calculating $\mu_{\text {efl }}$ are shown in Table 1 and are characteristic of early spring (February and March) in SSFB. As discussed in Lucas et al. (1999), near-uniform distributions of the key parameters (e.g. light attenuation coefficient and benthic grazing rate) are used for the sake of generality.

The TRIM-BIO simulations discussed in this paper are based on purely tidal hydrodynamics (i.e. no winddriven or density-driven flows are explored). To drive the tidal flow, water-surface elevation at the northern (open) boundary is specified; this time-variable boundary condition is based on 16 tidal constituents derived from SSFB field measurements (Cheng \& Gartner 1985). Phytoplankton biomass, $B$, at the northern boundary is either 0 or $3 \mathrm{mg} \mathrm{chl} \mathrm{a} \mathrm{m}^{-3}$, depending on the particular simulation. The initial condition for phytoplankton is $B=$ $3 \mathrm{mg} \mathrm{chl} \mathrm{a} \mathrm{m}^{-3}$ (a typical background value in SSFB), but varies spatially between simulations. 
Table 1 Physiological and environmental constants and calculated variables. Parameters are representative of South San Francisco Bay in early spring (Caffrey et al. 1994, Edmunds et al. 1995, Thompson 1999)

\begin{tabular}{|c|c|c|c|}
\hline Name & Units & Value/range & Description \\
\hline \multicolumn{4}{|c|}{ Independent variables } \\
\hline$t$ & d & & Time \\
\hline$x$ & $\mathrm{~m}$ & & Along-estuary distance \\
\hline$y$ & $\mathrm{~m}$ & & Cross-estuary distance \\
\hline \multicolumn{4}{|c|}{ Parameters } \\
\hline a & $\begin{array}{l}\left(\mathrm{mg} \mathrm{C}(\mathrm{mg} \mathrm{chl} \mathrm{a} \mathrm{h})^{-1}\right) \\
\left(\mu \mathrm{mol} \mathrm{m} \mathrm{m}^{-2} \mathrm{~s}^{-1}\right)^{-1}\end{array}$ & 0.031 & $\begin{array}{l}\text { Photosynthetic efficiency } \\
\text { at low irradiance }\end{array}$ \\
\hline$D$ & $\mathrm{~h}$ & 12 & Photoperiod \\
\hline$I(0)$ & $\mathrm{mol} \mathrm{m}^{-2} \mathrm{~d}^{-1}$ & 28 & $\begin{array}{l}\text { Total daily surface irradiance } \\
\text { (quantum flux, photosyntheti- } \\
\text { cally active radiation) }\end{array}$ \\
\hline$K_{\mathrm{h}}$ & $\mathrm{m}^{2} \mathrm{~s}^{-1}$ & 0 & Horizontal scalar diffusivity \\
\hline$k_{t}(x, y)$ & $\mathrm{m}^{-1}$ & $1.0-10.0$ & Abiotic light attenuation coefficient \\
\hline$p_{\max }$ & $\mathrm{mg} \mathrm{C}(\mathrm{mg} \operatorname{chl} a \mathrm{~h})^{-1}$ & 8.5 & $\begin{array}{l}\text { Maximum instantaneous } \\
\text { photosynthetic rate }\end{array}$ \\
\hline$T$ & ${ }^{\circ} \mathrm{C}$ & 13 & Water temperature \\
\hline$\alpha(x, y)$ & $\mathrm{m}^{3} \mathrm{~m}^{-2} \mathrm{~d}^{-1}$ & $0-10$ & Benthic grazing rate \\
\hline$\Delta x$ & $\mathrm{~m}$ & 200 & Along-estuary grid spacing \\
\hline$\Delta y$ & $\mathrm{~m}$ & 200 & Cross-estuary grid spacing \\
\hline \multicolumn{4}{|c|}{ Dependent variables } \\
\hline$B(x, y, t)$ & $\mathrm{mg} \operatorname{chl} a \mathrm{~m}^{-3}$ & & $\begin{array}{l}\text { Depth-averaged } \\
\text { phytoplankton biomass }\end{array}$ \\
\hline$H(x, y, t)$ & $\mathrm{m}$ & $0-20$ & Water column height \\
\hline$\mu_{\text {eff }}(x, y, t)$ & $\mathrm{d}^{-1}$ & & $\begin{array}{l}\text { Effective phytoplankton } \\
\text { growth rate }\end{array}$ \\
\hline$\mu_{\mathrm{eff}}^{\text {chan }}$ & $d^{-1}$ & & $\begin{array}{l}\text { Effective phytoplankton } \\
\text { growth rate in channel }\end{array}$ \\
\hline$\mu_{\text {eff }}^{\text {shodl }}$ & $\mathrm{d}^{-1}$ & & $\begin{array}{l}\text { Effective phytoplankton } \\
\text { growth rate in shoal }\end{array}$ \\
\hline
\end{tabular}

exchange flows, and Lagrangian chaos (Ridderinkhof \& Zimmerman 1992). Obviously, any processes which rely on vertical shear - especially dispersion via 2-layer exchange flows - cannot be resolved by a depth-averaged model $_{i}$ therefore, use of a model like TRIM2D requires that we either (1) parameterize those processes not resolved, or (2) assume that the model captures the most important dispersive processes for the cases of interest and not rely on parameterizations for subgrid-scale mechanisms.

Because the relative influence of each major dispersive process may vary enormously in space (Ridderinkhof \& Zimmerman 1992) and in time (Huzzey et al. 1990, Gross 1997), it is impossible to accurately cast all sources of large-scale estuarine dispersion in the form of a simple parameterization for a horizontal diffusivity (like $K_{h}$ ). Moreover, previous work has suggested that such approximations may not be necessary. Gross' (1997) TRIM2D simulations of salt transport in SSFB - with $K_{\mathrm{h}}$ set to zero-compared very closely both with measured salinity distributions in SSFB and with 3-dimensional model predictions. Gross (1997) found that, at the available spatial resolution $(200 \mathrm{~m})$, the key to successfully modeling scalar transport is accurate numerical representation of the advective processes. By resolving

As discussed below, high-quality calculation of scalar advective transport is crucial in this type of modeling effort. The Lax-Wendroff scheme with Roe's 'Superbee' flux limiter (Hirsch 1988, Gross et al. 1999) is thus implemented for scalar advection. Though computationally expensive, this scheme adds the minimum artificial diffusion necessary to prevent numerical oscillations and associated negative scalar concentrations in regions of sharp gradients.

\section{Horizontal dispersion}

There are many possible sources of large-scale dispersion in estuaries, including various shear flow dispersion mechanisms (i.e. interaction of cross-flow shear with cross-flow mixing, Zimmerman 1986), winddriven (Dronkers \& Zimmerman 1982, Walters et al. 1985) and baroclinic (Fischer et al. 1979, Gross 1997) the spatial gradients and the temporal evolution of the tidal velocity field, Gross (1997) was able to represent the dominant transport mechanisms without any need for an ad hoc representation of horizontal dispersion. Furthermore, we ran TRIM2D simulations both with $K_{\mathrm{h}}$ set (1) to zero and (2) to unrealistically large values (relative to turbulent approximations), and found that the results reported here would not change if $K_{\mathrm{h}}$ were nonzero. This knowledge, along with the fact that this paper focuses on purely tidal transport (i.e. no baroclinic or wind-induced flows are included), justifies our decision to set the horizontal diffusion coefficient to zero.

\section{TRANSPORT-RELATED MECHANISMS}

As we demonstrated in Lucas et al. (1999), the conditions controlling local net phytoplankton growth rates in an estuary may vary significantly in both space and 
time. As we will illustrate in this section, the combination of spatial-temporal variability in local conditions with large-scale horizontal transport determines if a bloom occurs and where it is located. We will show that, under some circunastances, residual transport can result in significant phytoplankton biomass accumulation in regions where local conditions are not conducive to rapid population growth. Subtidal transport can also result in surprisingly low biomass in regions where local conditions support high rates of biomass production. As Koseff et al. (1993) and Cloern (1991) demonstrated with respect to mixing in the vertical dimension, tidal-time-scale horizontal transport may provide frequent interaction between adjacent regions with different local production characteristics, resulting in unexpected degradation or enhancement of a bloom. We will demonstrate the following transportrelated mechanisms as potential controls on bloom development and location: (1) residence time/exporthow long material remains in a region; (2) import - the rate at which material is transported to a region; (3) role of channel as conduit-the system-wide significance of local conditions in a channel region in providing a large-scale residual vehicle for biomass transport; (4) physical-biological phasing - the relationship between tidal-time-scale changes in transport and local net phytoplankton growth rate ('buffer zones' provide an example of how this phasing may preserve a bloom) (5) lateral sloshing - the transfer of nearshore material to deep channel regions during ebb tide and its return to the shallower regions during flood tide.

\section{Residence time/export}

Figs. 2 \& 3 demonstrate the effect of residence time on the ultimate location of a bloom. In this example, we focus on the southeast shoal region of our domain, between the San Mateo and Dumbarton Bridges (see Fig. 1 for reference). Fig. 2a,b shows the positions at $t=0$ and $t=13 \mathrm{~d}$, respectively, of passive particles initialized along the eastern half of the southeast shoal. The positions of these particles, or numerical drogues, were calculated by the TRIM2D hydrodynamic model for purely tidal flow. The residence time in that southeast shoal region is evidently quite short, since most of the drogues are exported within 2 wk by a strong northward residual (tidally averaged) current.

The potential effect of a short residence time is illustrated in Fig. 3, which shows calculated distributions of effective phytoplankton growth rate $\left(\mu_{\text {efil }}\right)$ and phytoplankton biomass $(B)$ for 2 tidal phases at $t \approx 6 \mathrm{~d}$. For this scenario, $k_{\mathrm{t}}$ (abiotic light attenuation coefficient) and $\alpha$ (benthic grazing rate) were chosen such that the southeast shoal has high $\mu_{\mathrm{er}}$, with net population growth rates ranging from 0.1 to $1.3 \mathrm{~d}^{-1}$ over a tidal cycle (Fig. $3 a, c$ ). We circled the region of interest and named it Region A. Because of the high local effective growth rates in Region $\mathrm{A}$, we might expect a large bloom in that locality. However, we see in Fig. 3b,d that the chlorophyll levels in Region A are not especially high compared to the very large concentrations immediately to the north, where $\mu_{\text {efi }}$ is generally smaller. Thus, we conclude that some growth must be occurring in Region A, but that biomass accumulation there is relatively small due to the rapid export of biomass to the north.

Residence time has previously been observed to be important to bloom development. In SSFB during 1982, Huzzey et al. (1990) measured 3 periods of significant phytoplankton biomass accumulation over the northeast shoal, and observed that the end of each such bloom episode coincided with the occurrence of a large lateral (shoal-to-channel) flow pulse (see Figs. 2 \& 5 of Huzzey et al. 1990). In that case, a relatively long residence time in the northeast shoal allowed a large bloom to develop, until an episode of rapid export flushed the region, depleting it of phytoplankton biomass. Therefore, temporal shifts in physical forcing can modify the residence time (or export rate) of a particular region. The importance of residence time to bloom development has previously been discussed with respect to many other systems (Frid \& Mercer 1989, Muylaert et al. 1997, Valiela et al. 1997).

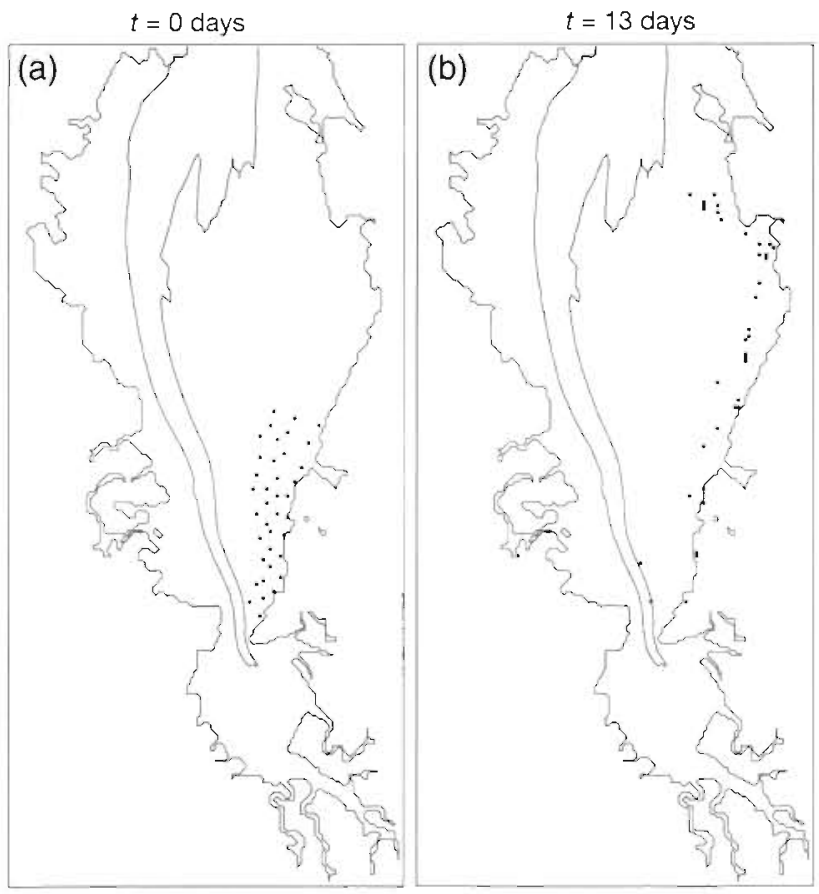

Fig. 2. Animation frames demonstrating short residence time in southeast shoal. (a) Initial position and (b) position at $t=$ $13 \mathrm{~d}$ of numerical drogues released in southeast shoal (south of San Mateo Bridge) 


\section{Low Tide}

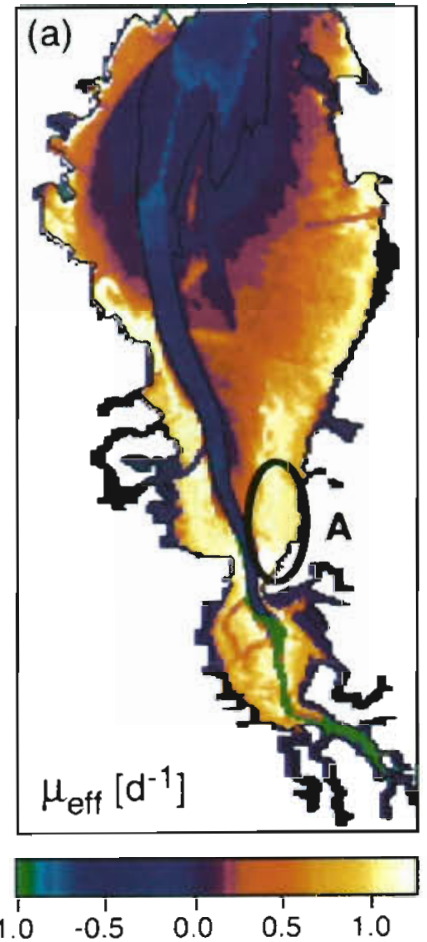

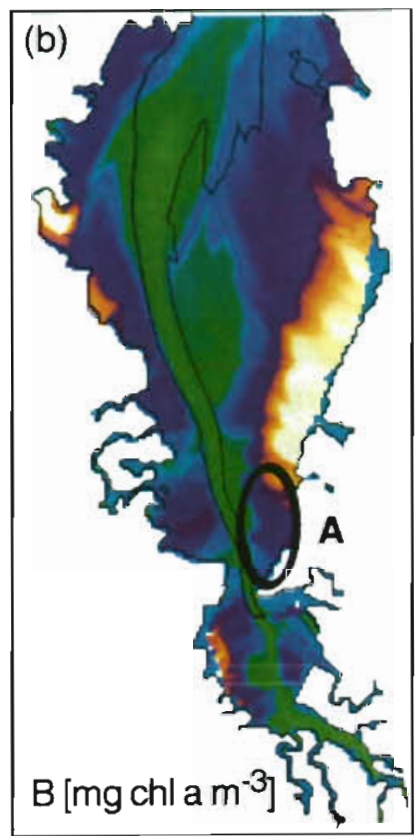

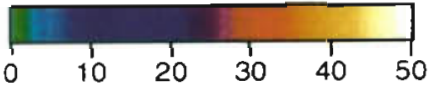

High Tide
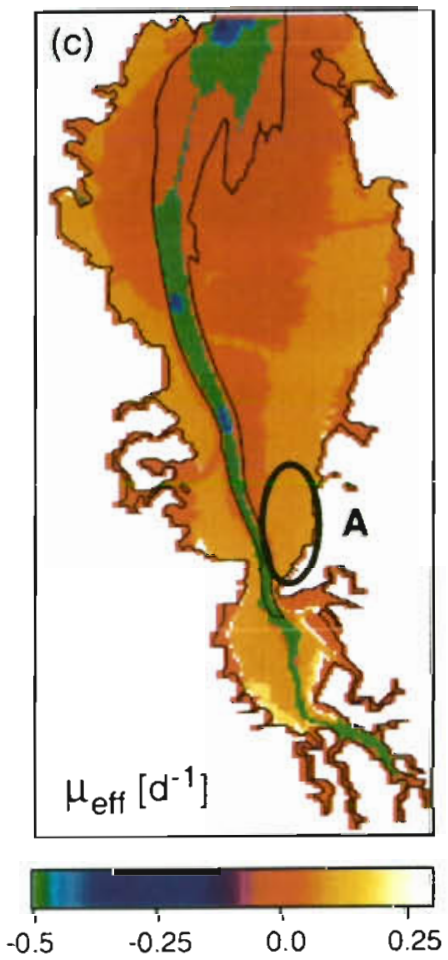
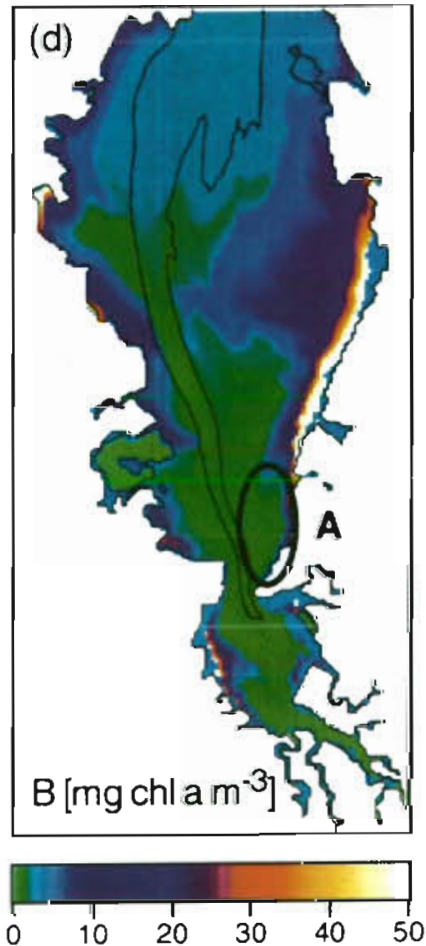

Fig. 3. Calculated (a) phytoplankton effective growth rate $\left(\mu_{\text {eff }}\right)$ and (b) phytoplankton biomass $(B)$ distributions at low tide, and (c) $\mu_{\text {elf }}$ and (d) $B$ distributions at high tide. Despite high local values of $\mu_{\text {eif }}$ in Region $A$, rapid export results in relatively low $B$ there

\section{Import}

Similar to the effect of export, biomass import can also control where a bloom is located. Fig. 4 demonstrates that biomass import can produce a significant bloom in an unproductive region. A TRIM-BIO simulation was run for a case where $\mu_{\text {eff }}$ and initial $B$ were set to zero everywhere except in the southeast shoal, where $k_{t}$ (turbidity) and $\alpha$ (benthic grazing) were specified so that $\mu_{\text {eff }}$ would be positive (Fig. 4a). The distribution of phytoplankton biomass at $t \approx$ 2 wk (Fig. 4 b) reveals a significant bloom not only in portions of the southeast shoal but also in the northeast shoal, where $\mu_{\text {eff }}$ and initial $B$ were zero. Clearly, the northward residual transport along the eastern shoal, as demonstrated by the particle tracks depicted in Fig. 2, is responsible. Thus, biomass import can produce a bloom in a region which is not itself a net source of phytoplankton biomass.

\section{Role of channel as conduit}

Another important aspect of large-scale subtidal transport in an estuary is the role a channel region plays as a conduit for dispersing mass throughout the domain. A deep channel may provide an effective route for mass transport because a larger inertia:friction ratio results in greater tidal excursion and higher residual velocities in a deep region than in a shallow region. Fig. 5 shows Eulerian (at a point in space) and Lagrangian (following a particle) residual velocity fields calculated for a day mid-way through the spring-neap cycle. The Eulerian residual field clearly shows that maximum mean velocities (averaged over 2 full tidal cycles) occur in the channel. In addition, both residual velocity fields suggest interaction between the channel and the adjacent shoals. For example, a gyre appears to exist in the vicinity of the San Mateo Bridge (see Fig. 1 for reference) on the eastern side of the channel. This gyre, which has been previously documented (Walters et al. 1985), allows a portion of the channel contents to spill into the eastern shoal over time. Such points of interaction between the channel and shoals, coupled with a large tidal excursion in the channel, produce great. potential for wide dispersal of channel contents throughout the estuary.

Drogues released in the northern channel demonstrate the importance of the channel's role 

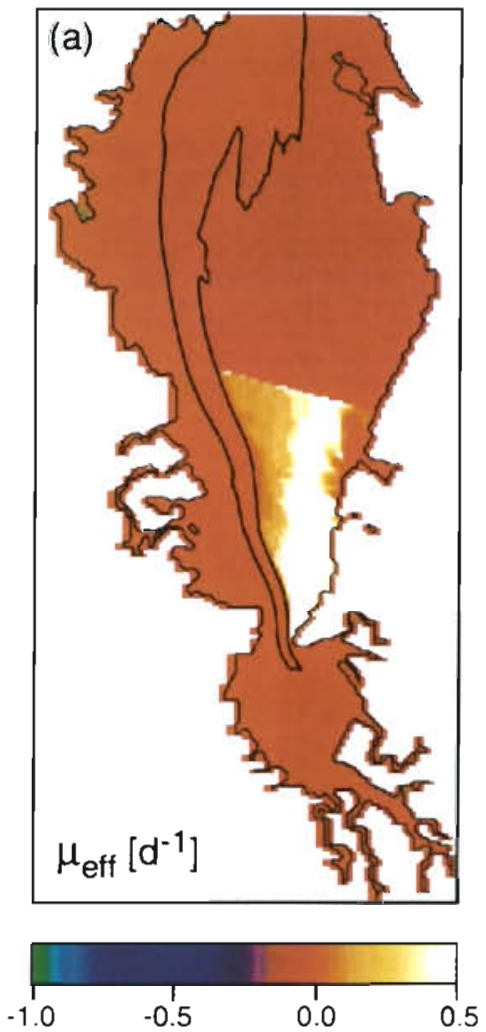

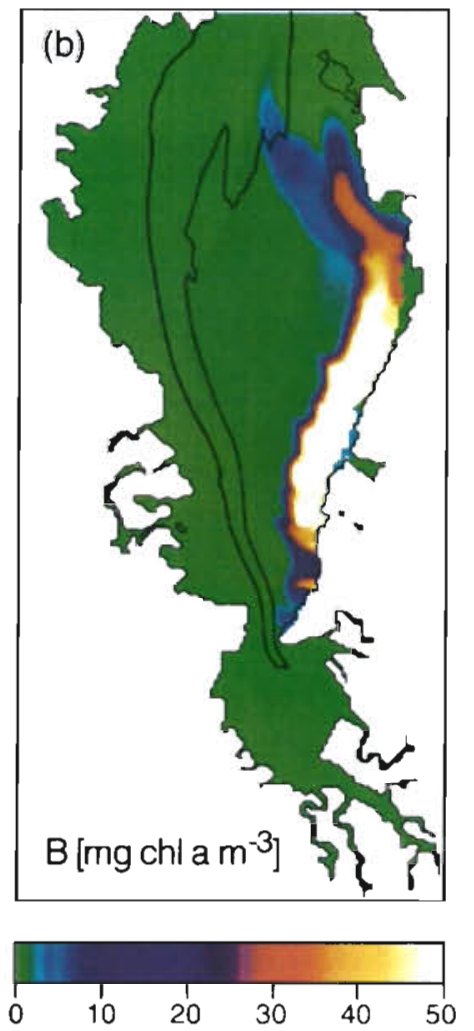

Fig. 4. Calculated (a) phytoplankton effective growth rate $\left(\mu_{\text {eff }}\right)$ and (b) phytoplankton biomass $(B)$ distributions at $t \approx 2 \mathrm{wk}$ for nonzero $\mu_{\text {eff }}$ only in the southeast shoal. Northeast shoal imports biomass grown in southeast shoal as mass conduit. Fig. 6 shows that particles initialized in the northern channel (Fig. 6a) are ultimately dispersed throughout the domain (Fig. 6b). At $t=13$ d (and at the same tidal phase as for the drogue release), a number of particles reside in the southern channel, eastern shoal, and northwest shoal. The particles in the eastern shoal at $t=13 \mathrm{~d}$ arrived there via the aforementioned gyre (near the middle of the domain) and continue to ride the northward residual currents toward the northeast shoal. The drogues remaining in the channel gradually travelled southward (due to the large southward residual currents in the channel) and, given enough time, would have entered the region south of the Dumbarton Bridge, at least during flood tide.

These transport patterns help us interpret the channel-conduit mechanism as it relates to phytoplankton biomass distribution. We ran 3 TRIM-BIO simulations, all with the same set of specified $k_{t}$ (turbidity) and $\alpha$ (benthic grazing) values in the western northeast shoal region (denoted as Region $\mathrm{i}$ in Fig. $7 \mathrm{a}$ and shaded with light yellow). The resultant values of $\mu_{\text {eff }}$ in Region i were always positive. Furthermore, in all 3 simulations initial phyto-
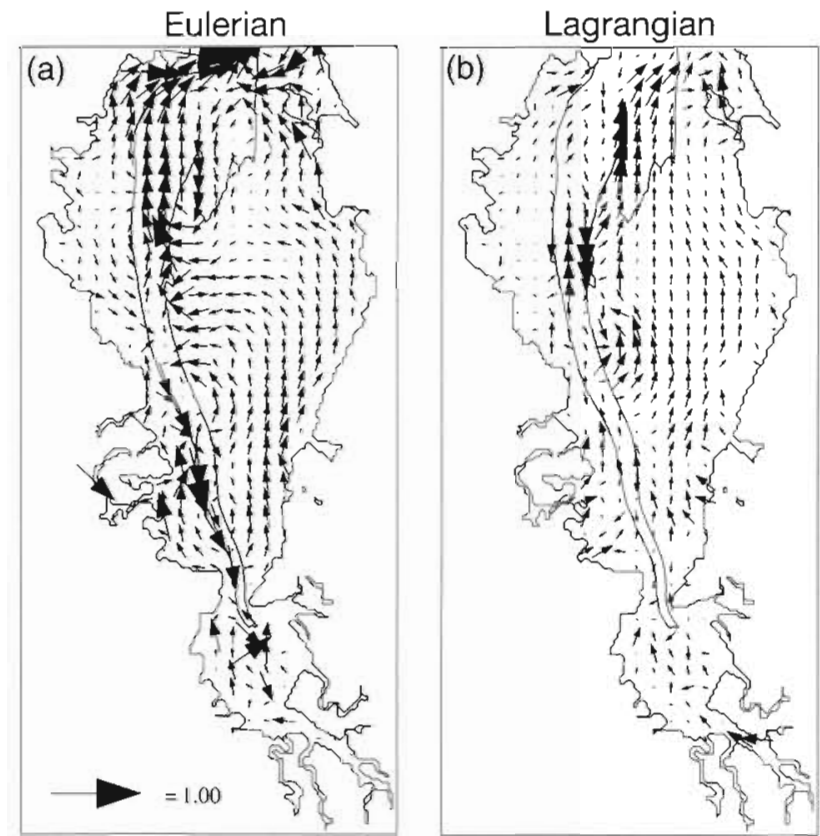

Fig. 5. (a) Eulerian residual velocity vectors and (b) Lagrangian residual velocity vectors calculated by TRIM2D for a day mid-way between peak spring and extreme neap. Calculated velocities are in $\left[\mathrm{m} \mathrm{s}^{-1}\right]$ and are purely tidal

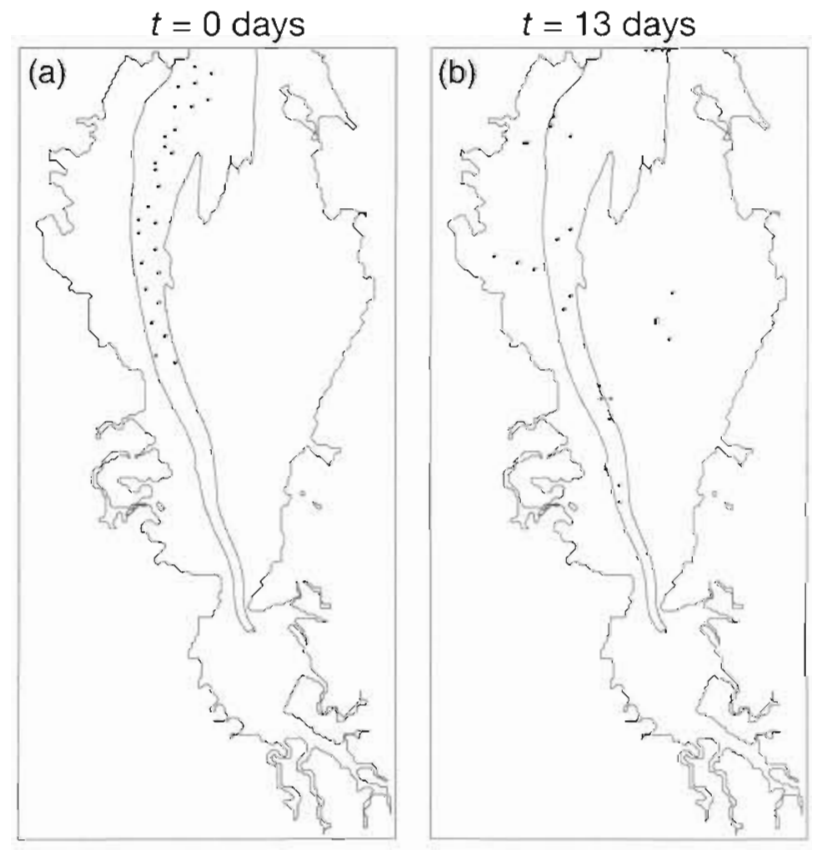

Fig. 6. Numerical drogues (a) initialized in northern channel and (b) dispersed throughout domain after tidal transport for $13 \mathrm{~d}$ 

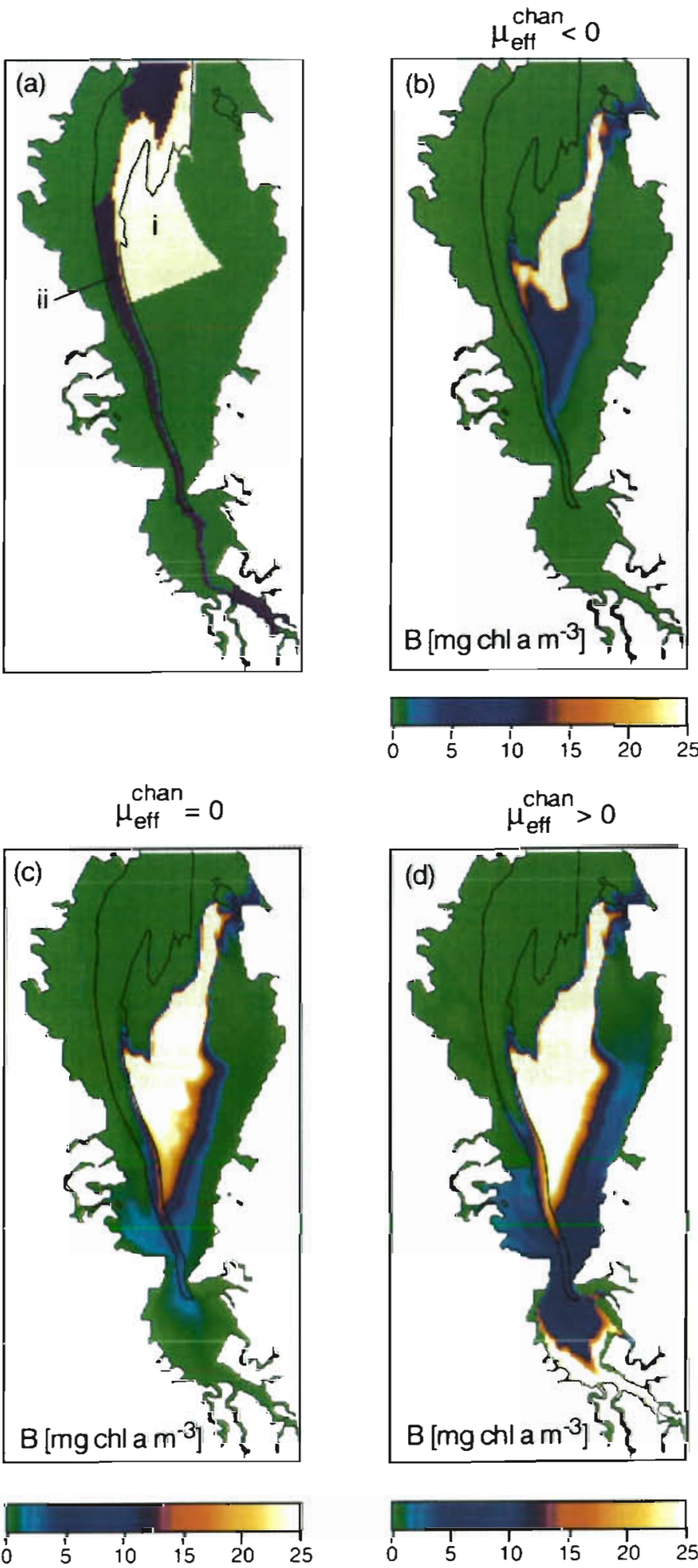

Fig. 7 (a) Regions of interest for channel-conduit simulations. Calculated phytoplankton biomass $(B)$ distributions after $-35 \mathrm{~d}$ for 3 channel growth rate scenarios: (b) $\mu_{\text {efi }}^{\text {chan }}<0$, (c) $\mu_{\text {ef }}^{\text {chan }}=0$, and (d) $\mu_{\text {eft }}^{\text {chan }}>0 . \mu_{\text {eff }}$ in Region i was always positive, and initial $B$ was zero everywhere but in Region i. $\mu_{e r l}$ outside of Regions $i$ and ii was always zero plankton biomass was zero everywhere except in Region i. The 3 simulations differed only by the specified $k_{1}$ and $\alpha$ values in the channel (denoted as Region if in Fig. $7 \mathrm{a}$ and shaded with purple). The resultant values of $\mu_{\text {eff }}^{\text {chan }}$ ( $\mu_{\text {eff }}$ in the channel) for the 3 scenarios were $\mu_{\text {eff }}^{\text {chan }}<_{1}=$, and $>0$ and correspond to Fig. $7 \mathrm{~b}, \mathrm{c}, \mathrm{d}$, respectively. $\mu_{\text {eff }}$ in the remainder of the domain (outside Regions $i$ and ii and shaded green in Fig. 7a) was set to zero. Thus, the only source of biomass to the domain was Region $i$, and the only regions of potential growth or decay were inside Regions $\mathrm{i}$ and ii.

For the case of $\mu_{\mathrm{ell}}^{\mathrm{chan}}=0$ (Fig. $7 \mathrm{C}$ ), the bloom originating in Region $i$ expands southward. This southward expansion of the bloom is enhanced by the process of spilling some biomass into the channel (notice the elevated channel biomass), which in turn feeds a portion of that biomass back into the southeastern shoal primarily via the aforementioned gyre. Notice also that chlorophyll concentrations are slightly elevated in the southwest shoal and in the region south of the Dumbarton Bridge.

For $\mu_{\mathrm{eff}}^{\text {chan }}<0$ (Fig. 7b), southward expansion of the bloom is not as extensive as for $\mu_{\text {eff }}^{\text {chan }}=0$; in fact, significantly elevated chlorophyll concentrations ( $B$ greater than about $10 \mathrm{mg} \mathrm{chl} \mathrm{a} \mathrm{m}^{-3}$ ) barely extend beyond Region i, and biomass in the channel is near zero. In this case, the channel cannot act as an effective conduit, because any biomass that enters the channel is quickly depleted by the negative values of $\mu_{\text {eff }}$ (generally $\approx-0.6 \mathrm{~d}^{-\mathrm{t}}$ ) there due to respiration and, primarily, large grazing losses ( $\alpha$ was set to $10 \mathrm{~m}^{3} \mathrm{~m}^{-2} \mathrm{~d}^{-1}$ in the channel). Caffrey et al. (1998), who measured pelagic production (PP) and pelagic respiration (PR) at a shallow site and a deep site in SSFB, found that PP is usually greater than PR in the shallows (i.e. for $\alpha=$ $0, \mu_{\text {eff }}^{\text {shol }}>0$ ), but that PP is usually less than PR in the channel (i.e. $\mu_{\text {eff }}^{\text {chan }}<0$ ). Therefore, the case of $\mu_{\text {eff }}^{\text {chan }}<0$ is a common occurrence in SSFB because pelagic respiration typically exceeds production in the channel. Large benthic grazing rates in a deep channel region, such as those greater than $10 \mathrm{~m}^{3}$ $\mathrm{m}^{-2} \mathrm{~d}^{-1}$ measured in SSFB (Thompson 1999), would result in more strongly negative values of $\mu_{\mathrm{eff}}^{\text {chan }}$ and could further constrain the large-scale distribution of a bloom.

For the case of $\mu_{\text {eff }}^{\text {chan }}>0$ (Fig. $7 \mathrm{~d}$ ), biomass distribution is much more extensive since conditions in the channel nurture the bloom as it is transported. Therefore, the channel is an effective vehicle for transporting a bloom if $\mu_{\text {eff }}^{\text {chan }} \geq 0$ (i.e. if respiration and grazing losses are less than or equal to production). 


\section{Physical-biological phasing}

The export, import, and channel-conduit mechanisms discussed above reflect subtidal, or residual, transport processes occurring over time scales of days or weeks. Other transport-related mechanisms affecting bloom development and location occur on tidal (hourly) time scales. An example is the concurrent quarter-diurnal shift in mass transport and local effective growth rates which can be significant in very shallow regions, where $\mu_{\text {eff }}$ is especially sensitive to shallowing and deepening of the water column over the semidiurnal tidal cycle (see Lucas et al. 1999). To illustrate a tidal transport pattern characteristic of some shoal regions, Fig. 8a,b shows the calculated locations, at consecutive high and low tides, of passive numerical drogues initially released in the southeast shoal. In this particular shoal region, it appears that particle transport includes a tidal-time-scale, cross-estuary oscillatory component, causing the particles to hug the shore during high tide, then allowing the particle patch to relax into the shoal interior during low tide. This behavior reflects tidal changes in water storage over the shoals: the water present in the shallowest regions during high tide may come primarily from deeper regions. In the southeast shoal, this tidal transport mechanism is superimposed on the overall northward residual transport pattern discussed in previous sections.
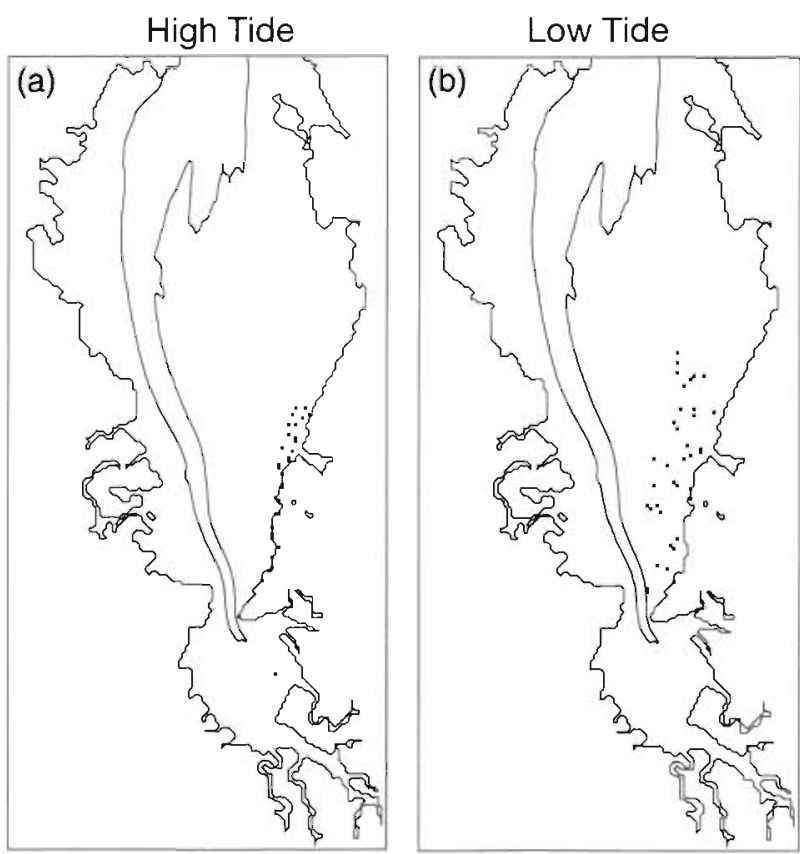

Fig. 8. Locations of numerical drogues in the southeast shoal during (a) high tide and (b) low tide, demonstrating a semidiurnal lateral displacement. Several drogues close to the eastern shore at highwater migrate to the shoal interior during ebb
The relative phasing of tidal-time-scale transport and temporally varying $\mu_{\text {eff }}$ can determine whether a bloom in a particular region is sustained or degraded. Fig. 9 presents an example of hydrodynamic-biological

\section{High Tide}
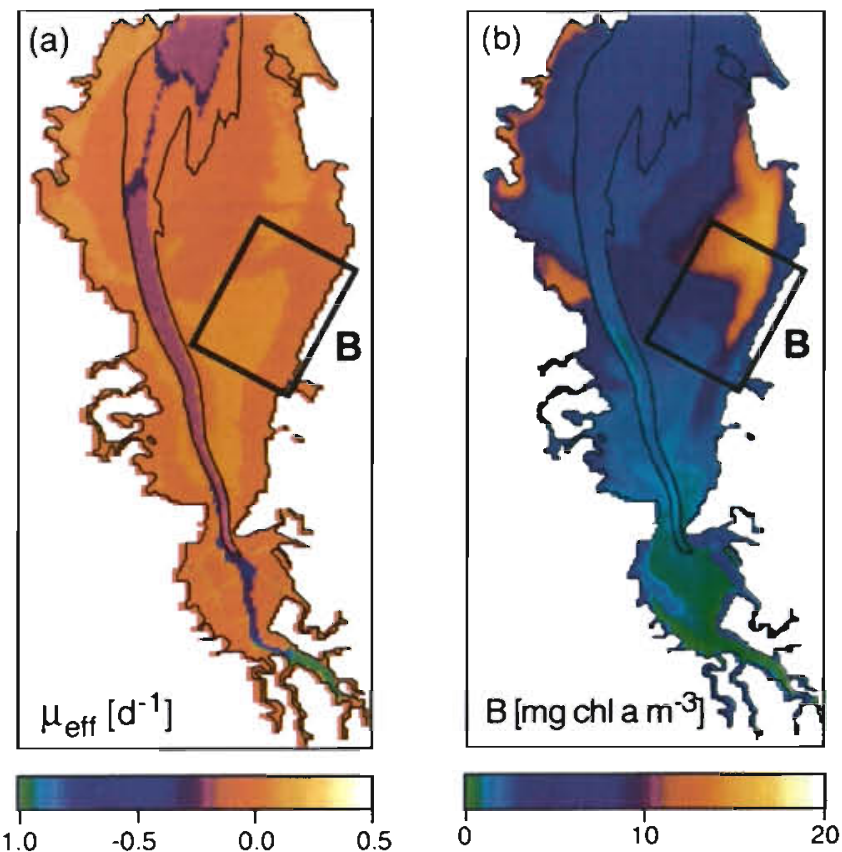

Low Tide
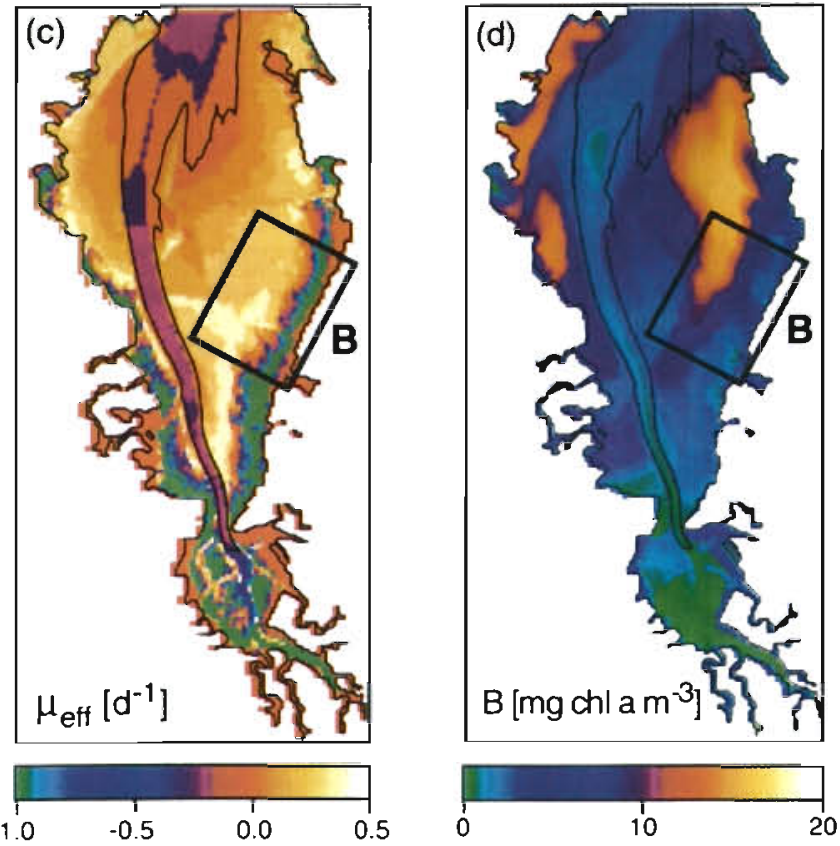

Fig. 9. Calculated (a) phytoplankton effective growth rate $\left(\mu_{\text {eff }}\right)$ and (b) phytoplankton biomass $(B)$ distributions at high tide, and (c) $\mu_{\mathrm{eff}}$ and (d) $B$ distributions at low tide, for nonzero benthic grazing in the shoal 
interaction on tidal time scales which helps sustain a bloom in the mid-east shoal in the presence of benthic grazing. As described in Lucas et al. (1999), effective growth rates in very shallow regions can be positive at high tide but negative at low tide if benthic grazing there is nonzero. This is due to enhanced depth-averaged benthic grazing losses as the water column shallows. We also showed that $\mu_{\text {eff }}$ in a deeper region is less sensitive to tidal shallowing and deepening. Fig. 9a,c shows snapshots of phytoplankton effective growth at high tide and low tide, respectively, for this scenario.

For the purpose of this discussion, we focus on a portion of the eastern shoal denoted as Region B. The nearshore portion of Region $B$ experiences negative $\mu_{\text {eff }}$ at low tide (Fig. 9c) but positive $\mu_{\text {eff }}$ during high tide (Fig. 9a). Fig. 9b,d shows snapshot chlorophyll distributions at the same simulation times. Like the drogues in Fig. 8, the phytoplankton patch in Region B expands into the shoal interior on ebb tide (Fig. 9d) and compresses against the shore on flood (Fig. 9b). The portion entering the mid-shoal, positive- $\mu_{\text {eff }}$ region during low water is preserved, and any remnant left behind near the shore is quickly depleted when $\mu_{\text {eff }}$ becomes negative there. During flood tide, the preserved portion of the phytoplankton patch sloshes back toward the shore, where $\mu_{\text {eff }}$ is then positive.

In this case $(\alpha>0)$, the mid-shoal region which receives nearshore phytoplankton on ebb tide is a 'buffer zone' between the strongly negative $\mu_{\text {eff }}$ nearshore and the low (and often negative) $\mu_{\text {eff }}$ in the adjacent channel. Thus, in the presence of benthic grazing, lateral oscillatory transport, coupled with the existence of such a buffer zone, allows a phytoplankton patch to avoid rapid depletion nearshore during low tide and then to hug the shore when effective growth rates there are maximal, thus preserving its elevated biomass. However, in the absence of grazing, this lateral expansion-compression of a phytoplankton patch may be suboptimal for a bloom, since in that case light would present the primary limitation and would be most abundant in the shallowest areas during low tide. Other mechanisms of hourly scale variability not included in TRIM-BIO-such as short-term variations in water column irradiance caused by tidally driven sediment resuspension and the diel light cycle-could contribute additional hourly scale physical-biological phasing processes.

The general idea of biomass being swept away from shore into the shoal interior on ebb tide and back on flood is consistent with previous observations in SSFB. For example, measurements by Cloern et al. (1989) in the mid-east shoal and channel during the 1987 spring bloom indicated biomass increase in the east shoal interior during ebb tide, with biomass increasing toward the shore (see Fig. 10). The authors suggested that, in addition to advection, local light-driven production and grazing losses of phytoplankton in the shallows are highly dynamic and may account for a significant portion of tidal-scale variability there.

\section{Lateral sloshing}

Another tidal-time-scale mechanism affecting blooms in a bathymetrically complex domain is lateral sloshing of material out of a shallow region and into a deep channel region on ebb tide, and then back into the shoal during flood tide. This mechanism is closely related to the physical-biological phasing described above but, in contrast, relies primarily on spatial variability in ef fective growth rates, as opposed to spatial-temporal variability. While the above physical-biological phasing mechanism depends on the existence of a 'buffer zone' between the nearshore and channel regions, lateral sloshing between shoal and channel relies on the absence of such a buffer zone and thus is related to the width of the shoal, bathymetric features, and lateral tidal excursion.

Consider the passive numerical drogues whose calculated locations at consecutive high and low tides are shown in Fig. 11a,b, respectively. These particles were initialized uniformly throughout the southwest shoal region denoted as Region $C$ (immediately north of the Dumbarton Bridge). A large number of the drogues in Region $C$ approach the western shore during flood and then enter the channel on ebb, due to the apparent absence of a buffer zone (as described in the previous section) between the nearshore and channel regions.

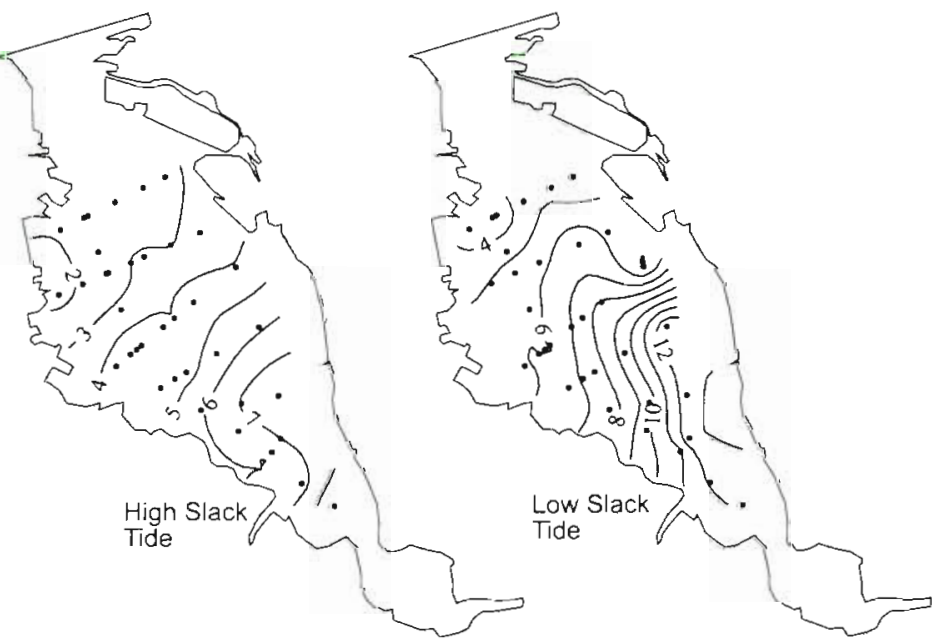

Fig. 10. Observed chlorophyll a distributions (in $\mathrm{mg} \mathrm{m}^{-3}$ ) in South San Francisco Bay on 7 April 1987 (from Cloern et al. 1989, Fig. 2) 

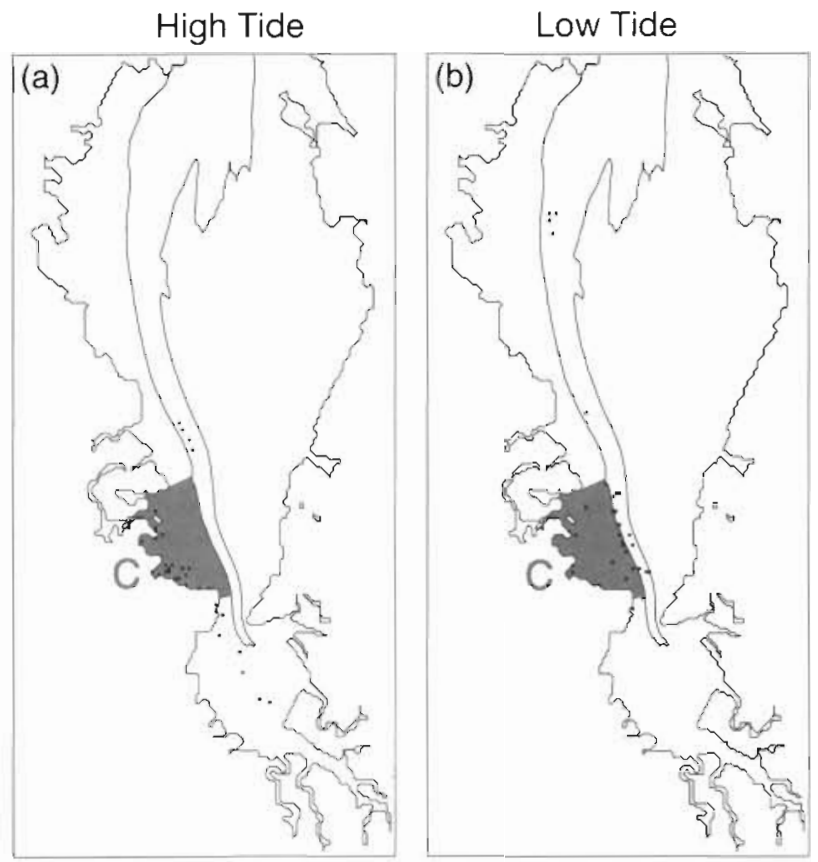

Fig. 11. Locations of numerical drogues initialized in southwest shoal (Region C) during (a) high tide and (b) low tide. Several of the drogues originating in Region C 'slosh' into the channel during ebb and return to the western shore during flood

In this way, biomass measured in Region $C$ is a product of conditions in the channel as well as in the southwest shoal. Thus, nonlocal conditions may contribute to what is observed locally.

Fig. 12 demonstrates that this is in fact the case. Three TRIM-BIO simulations were run for a condition in which effective growth rates were set to zero everywhere in the domain except in the southwest shoal (Region C) and in the channel. Values of $k_{t}$ (turbidity)

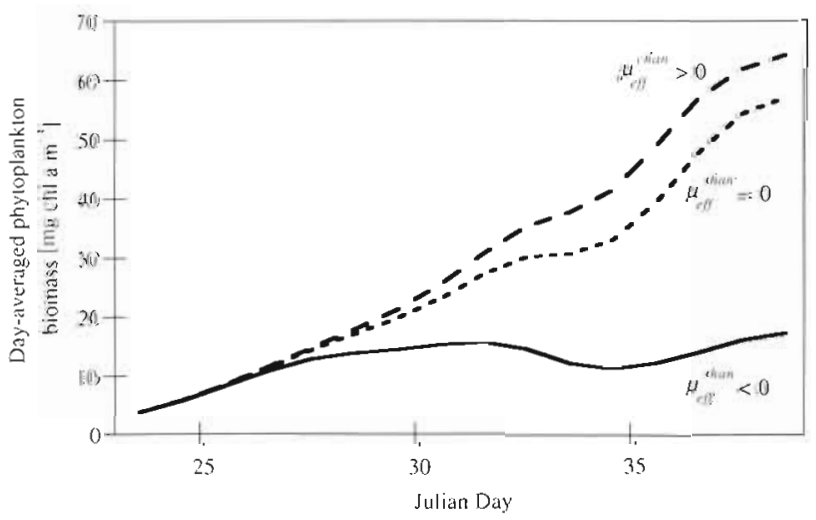

Fig. 12. Time series of calculated day-averaged phytoplankton biomass in the southwest shoal (Region C) for negative, zero, and positive effective growth rate in the channel ( $\left.\mu_{\text {efi }}^{\text {chan }}\right)$. For all 3 cases, $\mu_{\text {eff }}$ was zero everywhere but in Region $C$ and in the channel; the southwest shoal was the only initial source of biomass to the system and $\alpha$ (benthic grazing) were specified such that day-averaged $\mu_{\text {eff }}$ was positive in Region $C$. In addition, initial $B$ was set to zero everywhere but in Region $C$. The 3 simulations differed only by $\mu_{\text {eff }}^{\text {chan }}$ in one case, $k_{l}$ and $\alpha$ were specified such that $\mu_{\text {eff }}^{\text {chan }}$ was positive; in another case, $\mu_{\text {eff }}^{\text {chan }}$ was set to zero; and in the last case, $k_{t}$ and $\alpha$ were specified such that $\mu_{\text {eff }}^{\text {chan }}$ was negative. These conditions ensured that the southwest shoal was the only initial source of phytoplankton biomass to the system, and that growth and decay could only occur in the southwest shoal or in the channel.

Time series of day-averaged phytoplankton biomass at a sampling location in the center of Region $\mathrm{C}$ are shown in Fig. 12 for the 3 cases. First, we see that day-averaged phytoplankton biomass in the southwest shoal increases for zero $\mu_{\text {eff }}^{\text {chan }}$. Thus, in the absence of any growth or decay external to Region $C$, conditions in the southwest shoal alone are sufficient to induce a bloom locally. If $\mu_{\text {eff }}^{\text {chan }}$ is positive (in this case $\mu_{\text {eff }}^{\text {chan }} \approx$ $0.1 \mathrm{~d}^{-1}$ ), that bloom in the southwest shoal is enhanced. On the other hand, if $\mu_{\text {elf }}^{\text {chan }}$ is negative (in this case $\mu_{\mathrm{eff}}^{\text {chan }} \approx-0.6 \mathrm{~d}^{-1}$, due to a very large $\alpha$ in the channel), a bloom may never develop in the southwest shoal. Because we have eliminated external sources and sinks of biomass for Region C (except for the channel), and since our 'drogues' demonstrated that lateral sloshing between shoal and channel actually occurs, lateral sloshing appears responsible for the biomass increase/decrease calculated for Region $\mathrm{C}$ (relative to $\mu_{\text {eff }}^{\text {chan }}=0$ ) and shown in Fig. 12. An additional potential source of biomass to a locale like Region C (in the case of positive $\mu_{\mathrm{eff}}^{\text {chan }}$ ) is biomass growing in the channel which was initially seeded by the shoal. (In this case, biomass in the adjacent channel rises slightly to $\approx 1.5 \mathrm{mg} \mathrm{chl} \mathrm{a} \mathrm{m} \mathrm{m}^{-3}$ for $\mu_{\mathrm{eff}}^{\text {chan }}=0$ and $\approx 3.5 \mathrm{mg} \mathrm{chl} a \mathrm{~m}^{-3}$ for $\mu_{\text {eff }}^{\text {chan }}>0$ by Julian Day 38 , so here this effect would be very small.) Regardless of whether a single mechanism or a combination of mechanisms is responsible, this example demonstrates the effect of nonlocal conditions (here, the production-loss balance in the channel) on local bloom dynamics (in the adjacent shoal domain): observed biomass is a time integration of $\mu_{\text {eff }} \cdot B$ along Lagrangian particle paths.

\section{DISCUSSION}

We have used a vertically averaged model of a shallow estuary to explore mechanisms that arise from the interaction of transport with variability in local phytoplankton dynamics and that can control the development and location of phytoplankton blooms. Although we have demonstrated these interactions in the context of one particular estuary (South San Francisco 
Bay), we expect these mechanisms to be present in other similar systems but at intensities which may vary seasonally and spatially. In the presence of additional hydrodynamic forcings such as wind or freshwater flow, the tidally driven mechanisms discussed would likely be modified or superposed with other processes.

The 5 transport-related mechanisms we described are:

Residence time/export. We showed, for example, that in a region with a short residence time, phytoplankton biomass may not be high, despite local conditions favorable to bloom development (i.e. large phytoplankton growth rates). This process, which depends on residual transport, has been previously inferred in other systems.

Import. This subtidal transport mechanism allows an unproductive region (e.g. where phytoplankton growth rates are zero or negative) to sustain a bloom. If biomass import to an unproductive region is rapid relative to export and local losses, biomass will accumulate.

Role of channel as conduit. Deep regions were shown to be large-scale vehicles for mass transport within an estuary, due to the large tidal excursion and residual currents there. A channel region is most effective as a conduit for phytoplankton biomass if local conditions in the channel maintain or enhance that biomass (i.e. if phytoplankton growth rates in the channel are $\geq 0$ ).

Physical-biological phasing. Shifts in transport and local growth conditions on hourly time scales due to the semidiumal tide can either sustain or diminish a bloom. For example, when benthic grazing in the shoals is nonzero, phytoplankton growth rates nearshore can become negative as the tide begins to ebb. At the same time, a nearshore phytoplankton patch expands into the mid-shoal 'buffer zone', where positive growth is maintained and a portion of the originally nearshore bloom is preserved. In the absence of benthic grazing, phasing of transport relative to variations in water column irradiance could diminish a bloom

Lateral sloshing. Some shoal regions do not have intermediate buffer zones to receive nearshore biomass during ebb tide. Instead, mass originating in the shallowest areas during high tide sloshes laterally into the adjacent channel region during ebb, and then back to the shoal during flood. By this mechanism, local conditions in the channel can affect phytoplankton biomass in the shoal; in fact, $\mu_{\text {eff }}$ in the channel can control whether or not a bloom occurs in the shoal.

We demonstrated above that if net growth rates in the channel are negative (i.e. the channel is a net sink for phytoplankton biomass) then the channel will not be an effective means of dispersing biomass through the system, because any biomass which enters the channel will be rapidly depleted. However, if net growth rates in the channel are positive, then the channel may provide a very effective conduit for phytoplankton biomass. For example, if a highly productive shoal region supplies biomass to a nonsink channel region, which then transports that biomass over large distances, that biomass may then seed blooms in other shoal regions which have open communication with the channel.

Although the numerical model used in this study does not permit us to directly explore the role of vertical density stratification, the simulation results presented allow us to speculate in this regard. Vertical density stratification, which effectively raises net phytoplankton growth rates in the channel, could switch off the biomass sink typically represented by the channel under unstratified conditions (Koseff et al. 1993) and consequently switch on a large-scale mass dispersal mechanism. We are thus compelled to ask: Could density stratification in a deep channel region lead to a more widespread bloom by enhancing the dispersive ability of the channel? Field measurements in SSFB which could potentially address this question (i.e. which include measurements in both channel and shoal regions under both stratified and unstratified conditions) are limited. However, the few years in which channel and shoal chlorophyll measurements were taken are consistent with this idea of channel stratification enhancing the system-wide bloom. For example, 1980 (Cloern et al. 1985) and 1982 (Huzzey et al. 1990) were years when persistent stratification (as opposed to strain-induced periodic stratification which develops and erodes within a tidal cycle) developed in the channel during the spring. In these years, the blooms measured in both the channel and shoal were relatively widespread and large (e.g. maximum chlorophyll was about $40 \mathrm{mg} \mathrm{chl} \mathrm{a} \mathrm{\textrm {m } ^ { - 3 }}$ in 1980 and about

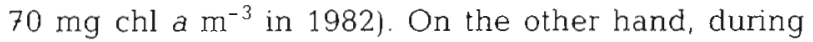
1987, a year of very low freshwater inflow to SSFB and at most only weak stratification in the channel, elevated chlorophyll concentrations were more localized and reached only about $12 \mathrm{mg}$ chl a $\mathrm{m}^{-3}$ (Cloern et al. 1989). Thus, field observations and simulation experiments suggest that, even if a bloom begins in a shallow region, the horizontal extent (and magnitude) of that bloom could be enhanced by the presence of density stratification in a deep channel region. This is an issue which can be explored directly with a 3-dimensional hydrodynamic-biological model.

Another general implication of this work is that modeling the tidal-time-scale variability of a transported scalar may be necessary if that scalar is reactive and dependent on its surroundings (unlike salt, 
for example). We have shown that tidal-time-scale processes - both physical and biological - can determine whether a bloom will occur. Mechanisms involving tidally driven oscillatory biomass transport between disparate environments, as well as the relative phasing of hourly-scale shifts in transport and biological processes, illustrate the importance of resolving tidal-time-scale variability in physical-biological dynamics. In a numerical model, such intratidal resolution is especially important when tidal excursions are equivalent to or greater than the length scales over which local growth conditions change significantly. Therefore, if spatial gradients in local conditions are sharp and tidal excursions are large, then a model should resolve intratidal processes. Furthermore, if local growth conditions vary significantly over a tidal cycle (as in a shallow region subject to benthic grazing), then intratidal variability should be considered. On the other hand, if spatial distributions of net growth rates are approximately uniform or tidal excursions are small, and if temporal variability of growth rates over a tidal cycle is minimal, then substituting tidally averaged (residual) representations for physical-biological dynamics may be reasonable. If available spatial resolution of the model domain is so coarse that a grid cell is on the order of or larger than the tidal excursion, then intratidal processes may not be captured, even if the time step is small; in this case, the benefits of resolving tidal transport may not be apparent.

Overall, we have demonstrated that local growth conditions, which depend on factors such as water column height, tidal amplitude, light availability, and grazing rates, determine if a bloom can occur. Thus, positive net growth somewhere in the estuary is necessary but not sufficient for a bloom to develop and certainly cannot tell us where a bloom will be observed. Large-scale transport plus spatial-temporal variability in local processes govern the conditions experienced by the phytoplankton while and after it grows, and thus determine if a bloom will occur and where it will be observed

Acknowledgements. L.V.L., J.R.K., and S.G.M. wish to acknowledge the support of the NSF Division of Biological Oceanography through grant number OCE-9504081, as well as the Josephine De Kármán Foundation, NASA, and the EPA through grant number CE00960502. J.E.C. and J.K.T. received support for this study from the USGS Toxic Substances Hydrology Program. We thank Vincenzo Casulli and Ralph Cheng for making the TRIM2D model available to us, Ed Gross for his help in implementing our additions, and Jon Burau and Ralph Cheng for the TRIM graphics routines which they developed and provided. L.V.L. performed this work as part of her dissertation research at Stanford University.

\section{LITERATURE CITED}

Burau JR, Monismith SG, Koseff JR (1993) Comparison of advective transport algorithms with an application in Suisun Bay, a sub-embayment of San Francisco Bay, California. In: Shen H W, Su S T, Wen F (eds) Hydraulic Engineering '93. American Society of Civil Engineers, New York, p 1628-1634

Caffrey JM, Cole BE, Cloern JE, Rudek JR, Tyler AC, Jassby AD (1994) Studies of the San Francisco Bay, California, estuarine ecosystem: pilot regional monitoring results, 1993. Open-File Report 94-82. US Geological Survey, Menlo Park, CA

Caffrey JM, Cloern JE, Grenz C (1998) Changes in production and respiration during a spring phytoplankton bloom in San Francisco Bay, California: implications for net ecosystem metabolism. Mar Ecol Prog Ser 172:1-12

Casulli V (1990a) Numerical simulation of shallow water flow. In: Gambolati G, Rinaldo A, Brebbia CA, Gray WG, Pinder GF (eds) Computational methods in surface water hydrology. Springer-Verlag, Berlin, p 13-22

Casulli V (1990b) Semi-implicit finite-difference methods for the two-dimensional shallow water equations. J Comput Phys 86:56-74

Cheng RT, Gartner JW (1985) Harmonic analysis of tides and tidal currents in South San Francisco Bay, California. Estuar Coast Shelf Sci 21:57-74

Cheng RT, Casulli V, Gartner JW (1993) Tidal, residual, intertidal mudflat (TRIM) model and its applications to San Francisco Bay, California. Estuar Coast Shelf Sci 36: $235-280$

Cloern JE (1991) Tidal stirring and phytoplankton bloom dynamics in an estuary. J Mar Res 49:203-221

Cloern JE, Cole BE, Wong RLJ, Alpine AE (1985) Temporal dynamics of estuarine phytoplankton: a case study of San Francisco Bay. Hydrobiologia 129:153-176

Cloern JE, Powell TM, Huzzey LM (1989) Spatial and temporal variability in South San Francisco Bay (USA). II. Temporal changes in salinity, suspended sediments, and phytoplankton biomass and productivity over tidal time scales. Estuar Coast Shelf Sci 28:599-613

Dronkers J, Zimmerman JTF (1982) Some principles of mixing in tidal lagoons. Oceanol Acta SP:107-117

Edmunds JL, Cole BE, Cloern JE, Caffrey JM, Jassby AD (1995) Studies of the San Francisco Bay, California, estuarine ecosystem: pilot regional monitoring results, 1994. Open-File Report 95-378. US Geological Survey, Menlo Park, CA

Fischer HB, List EJ, Koh RCY, Imberger J, Brooks NH (1979) Mixing in inland and coastal waters. Academic Press, Inc, San Diego, CA

Frid CLJ, Mercer TS (1989) Environmental monitoring of caged fish farming in macrotidal environments. Mar Pollut Bull 20(8):379-383

Gross ES (1997) Scalar transport in South San Francisco Bay. $\mathrm{PhD}$ thesis, Stanford University

Gross ES, Koseff JR, Monismith SG (1999) Evaluation of advective schemes for salinity simulations. J Hydrol Eng 125(1):32-46

Hirsch C (1988) Numerical computation of internal and external flows, Vol 1. Fundamentals of numerical discretization. John Wiley and Sons Ltd., Chichester

Huzzey LM, Cloern JE, Powell TM (1990) Episodic changes in lateral transport and phytoplankton distribution in South San Francisco Bay. Limnol Oceanogr 35(2):472-478

Koseff JR, Holen JK, Monismith SG, Cloern JE (1993) Coupled effects of vertical mixing and benthic grazing on 
phytoplankton populations in shallow, turbid estuaries. $J$ Mar Res 51:843-868

Lucas LV, Koseff JR, Cloern JE, Monismith SG, Thompson JK (1999) Processes governing phytoplankton blooms in estuaries. I: The local production-loss balance. Mar Ecol Prog Ser 187:1-15

Muylaert K, Kerckvoorde AV, Vyverman W, Sabbe K (1997) Structural characteristics of phytoplankton assemblages in tidal and non-tidal freshwater systems: a case study from the Schelde basin, Belgium. Freshw Biol 38(2): $263-276$

Ridderinkhof $H$, Zimmerman JTF (1992) Chaotic stirring in a tidal system. Science 258:1107-1111

Editorial responsibility: Otto Kinne (Editor),

Oldendorf/Luhe, Germany
Thompson JK (1999) The effect of infaunal bivalve grazing on phytoplankton bloom development in South San Francisco Bay. PhD thesis, Stanford University

Valiela I, McClelland J, Hauxwell J, Behr PJ, Hersh D. Foreman K (1997) Macroalgal blooms in shallow estuaries: controls and ecophysiological and ecosystem consequences. Limnol Oceanogr 42:1105-1118

Walters RA, Cheng RT, Conomos TJ (1985) Time scales of circulation and mixing processes of San Francisco Bay waters. In: Hydrobiologia 129:13-36

Zimmerman JTF (1986) The tidal whirlpool: a review of horizontal dispersion by tidal and residual currents. Neth J Sea Res 20(2/3):133-154

Submitted: September 1, 1998; Accepted: May 10, 1999

Proofs received from author(s): September 27, 1999 